\title{
A Study of Customer Satisfaction with Special Reference to High Speed Harmain Railways Services in Saudi Railways
}

\author{
Mohamed Jamil, Mohamed Sarraj, Khalid Ibrahim, Abdulmagid Aljohani \\ Master Students \\ College of Business Administration \\ University of Business \& Technology, Jeddah, Saudi Arabia \\ Sayeeduzzafar Qazi* \\ Professor \\ College of Business Administration \\ University of Business \& Technology, Jeddah, Saudi Arabia
}

\begin{abstract}
Nowadays customer satisfaction is intensively discussed and analyzed because all organizations of any type are relying on highly satisfied customers to achieve success, growth and sustainability, especially in service sector. Numerous theoretical and empirical studies show a positive relationship between customer satisfaction and plenty of factors that influence that. In this paper we are trying to measure the level of customer satisfaction with the services offered by the Saudi railways (haramin high speed rail HHR), investigate the passenger's perception about the service quality, and try to identify different ways to improve the service quality in both the stations and on board. A survey was conducted on 248 passengers for this research. The survey consists of 18 fixed alternative questions and one open ended question for suggestions and remarks. The survey questions cover three main categories the stations, service on board and catering (6 questions each). To analyze the data an average was calculated for each category and for each question with gender based demographic segmentation. As a result, different areas for improvement have been recognized. The results also indicate that the passengers perceive that quality of services delivered to them is relatively satisfactory. This paper can be viewed as starting point for future research regarding Haramain high speed rail.
\end{abstract}

Keywords: High Speed Rail, Entertainment Service, Catering Quality, Customer satisfaction, Harmain railways DOI: $10.7176 / \mathrm{EJBM} / 11-9-18$

Publication date:March $31^{\text {st }} 2019$

\section{Introduction:}

The Saudi government has taken a decision to implement a railway project linking the holy cities of Makkah and Madinah via Jeddah. The HHR (haramin high speed rail), also known as the Medina-Mecca High-Speed Train, is a $449.2 \mathrm{~km}$ long rail system set up for a high-speed train operation, which links the holy cities of Islam, Mecca and Medina via Jeddah, King Abdul-Aziz International Airport (KAIA), and King Abdullah Economic City (KAEC). The Haramain high-speed train is designed to provide a quality service (safe, comfortable, fast and punctual) through electric passenger trains that will run at a maximum speed of $320 \mathrm{~km} / \mathrm{h}$. The HHR system is expected to transport millions of passengers per year, including Hajj and Umrah pilgrims, so as to reduce traffic congestion on the roads and environmental pollution caused by car emissions. Haramain High Speed Rail project represents one of the most important transport project in the expansion program of Saudi railway network. The project was approved by the supreme Economic Council under the resolution No. 3/23 dated 23/3/1423, which included that the project is to be implemented on Build, Operate and Transfer (BOT) basis with participation of private sector. Haramain High Speed Project is considered an urgent need at the present time for several reasons, the foremost of these reasons is the growing number of pilgrim year after year, as well as the Umrah performers, visitors and residents who come to Makkah and Madinah throughout the year particularly during the seasons and holidays. The trains have been equipped with latest signaling and communications system. As part of the different stages within the Haramain High Speed Rail project, it has been planned to carry out a Service Demonstration program. The Service Demonstration will commence on December 29th 2017 and will take place over a period of 10 weeks during the weekends. This program will be useful for testing the functioning of the HHR track and systems, and the commercial aspects of the service. Trains will run between Makkah and Madinah, with a stop in King Abdullah Economic City. 
Table 1: showing general information (distances in KM and time in minutes) about HHR.

\begin{tabular}{|c|c|c|c|c|c|}
\hline \multicolumn{7}{|c|}{ DISTANCES IN KM } \\
\hline & Makkah & Jeddah & Jeddah Airport & KAEK & Medinah \\
\hline Makkah & & 78,3 & 98 & 181 & 449 \\
\hline Jeddah & 78,3 & & 19,6 & 104 & 371 \\
\hline Jeddah Airport & 98 & 19,6 & & 84 & 102 \\
\hline KAEK & 181 & 104 & 84 & & 267 \\
\hline Medinah & 449 & 371 & 102 & 267 & \\
\hline
\end{tabular}

\begin{tabular}{|c|c|c|c|c|c|}
\hline \multicolumn{7}{|c|}{ TIME IN MINUTES / GENERAL SERVICE PHASE } \\
\hline & Makkah & Jeddah & Jeddah Airport & KAEK & Medinah \\
\hline Makkah & & 25 & 31 & 64 & 132 \\
\hline Jeddah & 25 & & 13 & 35 & 103 \\
\hline Jeddah Airport & 31 & 13 & & 34 & 351 \\
\hline KAEK & 64 & 35 & 34 & & 65 \\
\hline Medinah & 132 & 103 & 351 & 65 & \\
\hline
\end{tabular}

Today customer satisfaction is widely discussing and analyzing because all organizations want that their customers would be satisfied and fascinated. Numerous theoretical and empirical studies show a positive relationship between customer satisfaction and plenty of factors that influence that. Nowadays customer satisfaction is one of the key goals in both smaller and larger organizations. In service sector it is exceptionally important because customer satisfaction is probably the main "key" to a successful business, recognition and retention of customers because service processes more or less involve the customer. Companies look for ways to find out customer's desires but at the same time want to ensure their satisfaction with services.

Going back to the 1950-1990 year as the authors Szwarc (2005) and Hill et al. (2007) tell hardly anyone spoke very much about customer service during that period. Organizations did not focus as much time and attention on customer service and the concept of customer satisfaction. Only in the last few years, organizations started to explore more on services and their provision of development and offer to customers. Therefore, it's meaningful to find out wider what is the opinion of most scientists and how they define the particular concept of customer satisfaction and how they understand and describe the customer satisfaction on services.

Firstly, as stated by Cochran (2003), satisfaction can mean basically anything that relates to the purchase of the organization. This may be due to factors such as price, execution time, comfort, responsiveness, reliability, benefits, and the same author argues that all the variables and more like a complex "mix" which fits to this definition. Vavra (2002) points out that customer satisfaction and the definition also depend on the specificity of a given object so the author mentions that satisfaction may be of a product, decision, process, delivery terms, the use of experience as a store or company, organization, and prior to the purchase of available expertise and so on.

As Hill et al. (2007) stated their opinion: there are many words and phrases that fit into this concept - and the customer loyalty, their relationships and experience, attention, admiration, service quality, emotional attachment, and so on. List could go on and on because there are so many phrases, but each of them describes the same phenomenon - the views and feelings that customer perceive his/her experience of receiving the service. Meanwhile, as Hill et al. (2007) cited in their book, perhaps the clearest and best definition was told by American marketing expert Philip Kotler: "If the service meets the expectations of the customer is satisfied and, if exceeding the expectations of customer remain highly satisfied; well, if the result does not meet expectations, then the customer remains dissatisfied, without exception, the service". Dulskis (2010) identifies the following consumer satisfaction factors: service provision, its quality, accessibility, the delivery rate (efficiency), professionalism, informative service, understanding the customer, friendly staff, their attitude and attention and the physical environment. In this paper a survey was made to measure the level of customer satisfaction regarding the Stations, on board services and Catering services.

\section{Review of Literature:}

Selvarani and Murugan (2017) studied Passenger's perception towards Indian railway service with reference to Villupuram junction. Primary data were collected from 100 passengers in the Villupuram Railway Junction with the help of questionnaire. The researcher contributes many service factor which are best suitable for railway to consider in future for satisfying the passengers in Villupuram.

European Commission, Directorate General for Mobility and Transport (2016) asked Gleave to investigate rail fare levels and service quality offered to passengers across the European Union and to assess how this has been influenced by policy in different Member States. In delivering this study a combination of desk research, stakeholder questionnaires and interviews were used. A key objective for the study was to determine how far fare 
policy in each of these areas has influenced the attractiveness of suburban, regional and long-distance rail services operating on routes on the main European rail network. The study covers all 26 members of the European Union which have operating railways (Cyprus and Malta have no operating railways), as well as Norway and Switzerland. Within the scope of this study it has not been possible to isolate the impact of fares and service quality measures from those other factors that influence rail demand. Fares and service quality are nevertheless important drivers of demand, and a substantial and growing body of empirical research quantifies these impacts.

Priyadharshini and Selladurai (2016) studied the service quality and passengers' satisfaction of southern railways by ServQual Model. The main aim of the study is to identify the socio economic background of railway passengers and to analyze the gap between passenger's expectation and perception of service quality.

Maheswari and Kumar (2015) studied Passenger Satisfaction of Amenities provided by Southern Railways in India. The objective of the study was to know the profile of Indian Railway and to know the level of satisfaction of public regarding the facilities provided to them by the Railway Department. The data's need for the study was collected through questionnaire method as a primary data and by secondary data. The collected data were analyzed using statistical methods like chi-square test. The sample size decided for the study was 200.The findings of the study was there was a significant relationship between the independent variable with level of satisfaction and it was proved by analysis.

Marinov et al (2014) analyzed the costumer services in Newcastle central station. the objective of this paper was to develop and employ a simple method for analyzing the customer satisfaction in railway stations to help us identify ways for improving both the customer service and the station design. a survey used to collect the necessary data for analysis. A comparison of the opinions of different categories of rail station users has been undertaken. As a result, different areas for improvement have been identified.

Rajeswari and Kumari (2014) investigated the passengers' perceptions about the service quality of rail transport system in Indian Railways while travelling between the major cities especially from Kerala to Delhi, Mumbai and Delhi. A modified SERVQUAL instrument including eight service quality constructs: Reliability, assurance, tangibles, timeliness, responsiveness, information system, empathy, food and safety and security were employed to measure the passengers" perceptions about the service quality of railways. Out of 500 respondents, only 442 were selected and these respondents were frequent railway traveler on these routes. Results indicate that passengers perceive that quality of services delivered to them is not satisfactory.

Geetika and Nandan (2010) studied the components of service quality of Indian Railways at railway platforms. The study was exploratory in nature and uses factor analysis to identify the most important factors of customer satisfaction with service quality. The research methodology was empirical, and a survey of passengers (customers) was conducted. The findings reveal that five factors are considered important for determining satisfaction with railway platforms, the most important of which are refreshments and behavioral factors.

\section{Objective of the Study:}

This research was carried out to measure the level of satisfaction upon the haramin high speed rail passengers, and to examine and assess the quality of services offered based on the perception of the passengers. Another objective of this research is to identify different area that need improvement and provide suitable recommendations and suggestions.

\section{Research Methodology: \\ SAMPLE:}

The research were conducted on 259 randomly selected passengers of Harmain Railways on board passengers. After scrutiny of the filled data 11 questionnaires were rejected because of various reasons like incomplete information, wrong entries etc. The remaining 248 cases were used in this study.

\section{PROCEDURE:}

Data was collected by survey method using on board Travelers in Harmain Railways. They were asked to properly go through the instructions and fill the given questionnaire based on their experience with the facilities offered by the Harmain Railways.

\section{TOOLS USED:}

A questionnaire were developed to identify the satisfaction level on three major dimensions includes Station facility, Onboard facility and catering facilities for Passengers using Harmain Railways. A total of 18 questions were framed related with the services and perception of the travelers using Likert type scale ranging from five (very satisfied) to one (very dissatisfied) with neutral midpoint. The costumers were instructed to write down their name and Email address before taking the survey. An extra open-ended question was available after each major dimension for suggestions and other remarks.

The data has been analyzed by using suitable statistical tools to achieve the objective of the research. 


\section{Results and Discussions:}

Transport plays an important role in providing what people needs in their daily live. Among the various means of transport, the railways hold the credit of providing more advantages to the passengers. The final success of railways depends upon the degree of satisfaction of the passengers or costumers. The level of satisfaction of the railway passengers largely depends on the extent to which needs are being fulfilled. It is necessary for the railways to assess the level of satisfaction of its passengers in order to build its name and reputation.

Table 3. showing the level of satisfaction for the station part of the survey and the average score for each statement.

\begin{tabular}{|l|l|l|l|l|l|l|}
\hline STATION & \multicolumn{3}{|c|}{ Average 1 } \\
\hline score & 5 & 4 & 3 & 2 & 1 & \\
\hline Staff attention on Station & 227 & 11 & 0 & 7 & 3 & 4.82 \\
\hline Ease and quick getting the ticket on station & 219 & 11 & 4 & 9 & 5 & 4.73 \\
\hline Cleanliness inside the station & 209 & 7 & 3 & 1 & 28 & 4.48 \\
\hline Uniform and dress code of the staff & 213 & 11 & 5 & 2 & 17 & 4.62 \\
\hline Easy and quick access to the train & 222 & 6 & 4 & 11 & 5 & 4.73 \\
\hline Information on station & 228 & 2 & 6 & 5 & 7 & 4.77 \\
\hline
\end{tabular}

\begin{tabular}{|l|l|l|}
\hline & average \\
\hline & males & females \\
\hline statement1 & 4.72 & 4.92 \\
\hline statement2 & 4.75 & 4.72 \\
\hline statement3 & 4.24 & 4.71 \\
\hline statement4 & 4.74 & 4.51 \\
\hline statement5 & 4.91 & 4.57 \\
\hline statement6 & 4.78 & 4.76 \\
\hline
\end{tabular}

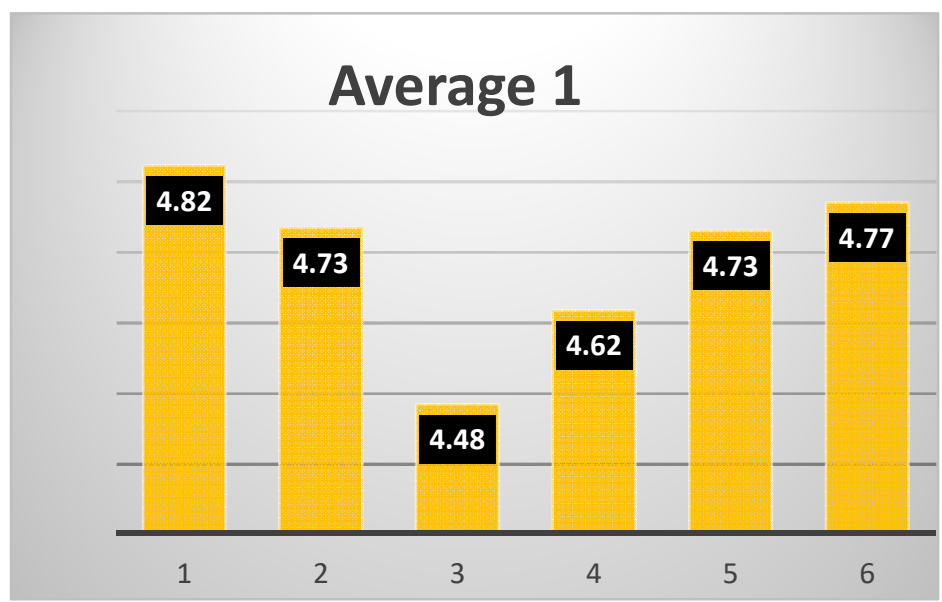

Table 3. Reveals a relatively high level of satisfaction regarding the station services. We expect the level of satisfaction to be high due to the fact that railway services are fairly new in Saudi Arabia and a lot of passengers might not have a past experience to compare with. 28 passengers graded a score of 1 for the third statement which means that there are highly dissatisfied with the cleanliness of the station facilities, also the average for the third statement is relatively low compared to the other statement (4.48), which may indicate a problem in the cleanliness inside the station. Males showed a higher level of dissatisfaction regarding the third statement compared to female averaging a score of 4.24. in the open ended part of the survey 22 passengers stated that the station in general is not clean enough. 
Table 4. showing the level of satisfaction for the service on board part of the survey and the average score for each statement.

\begin{tabular}{|l|l|l|l|l|l|l|}
\hline SERVICE ON BOARD & 5 & 4 & 3 & 2 & 1 & \\
\hline score & 211 & 11 & 3 & 16 & 7 & 4.63 \\
\hline Staff attention on board & 185 & 9 & 7 & 17 & 30 & 4.22 \\
\hline Entertainment on board & 234 & 4 & 2 & 6 & 2 & 4.86 \\
\hline Information on board during the trip & 216 & 7 & 6 & 14 & 5 & 4.67 \\
\hline Uniform and dress code of the staff & 226 & 7 & 2 & 4 & 9 & 4.76 \\
\hline Cleanliness on board & 237 & 2 & 8 & 0 & 1 & 4.91 \\
\hline Comfortability during the trip & & \\
\hline
\end{tabular}

\begin{tabular}{|l|l|l|}
\hline & males & females \\
\hline statement7 & 4.61 & 4.64 \\
\hline statement8 & 4.20 & 4.23 \\
\hline statement9 & 4.89 & 4.84 \\
\hline statement10 & 4.68 & 4.67 \\
\hline statement11 & 4.66 & 4.85 \\
\hline statement12 & 4.89 & 4.93 \\
\hline
\end{tabular}

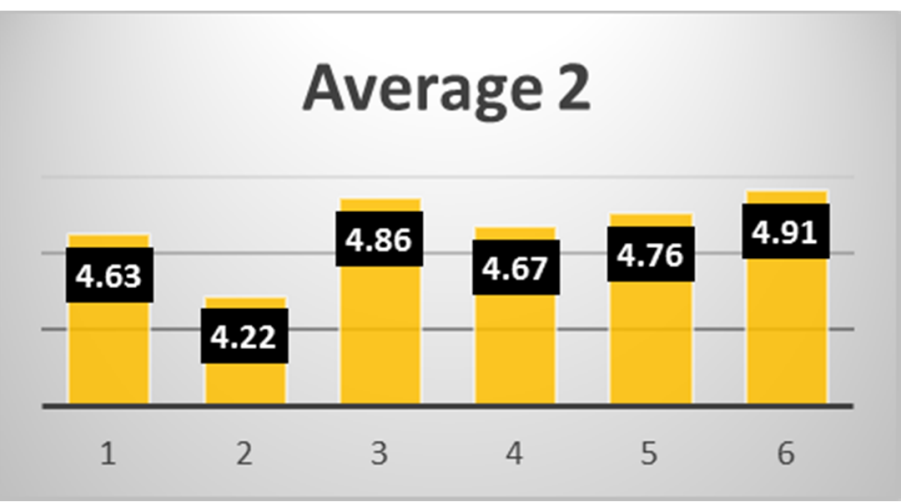

Table 4. reveals a relatively high level of satisfaction regarding the service on board. 30 passengers graded the eighth statement with the score of 1 and 17 passengers with the score of 2 which reveals that they are dissatisfied with the entertainment on board. That might be due to the absence of entertainment screens in the economic class or due to the religious nature of the trip that they might find movies, series etc. inappropriate. Both males and females showed a relatively low average for the eighth statement (4.20) (4.23) respectively compared to other statements. In the open ended part of the survey 27 passengers addressed the need for an USB port and 183 passengers complained about the lack of network coverage and Wi-Fi network during the trip. 
Table 5. showing the level of satisfaction for the catering part of the survey and the average score for each statement.

\begin{tabular}{|l|l|l|l|l|l|l|}
\hline CATERING & 5 & 4 & 3 & 2 & 1 & \\
\hline score & 229 & 10 & 0 & 8 & 1 & 4.85 \\
\hline Presentation of the food & 187 & 8 & 8 & 24 & 21 & 4.27 \\
\hline Variety of the Menu & 222 & 8 & 3 & 6 & 9 & 4.73 \\
\hline Courtesy of the staff & 219 & 10 & 4 & 1 & 14 & 4.69 \\
\hline Uniform and dress code of the staff & 185 & 14 & 13 & 21 & 15 & 4.34 \\
\hline Quality of the food & 196 & 25 & 4 & 15 & 8 & 4.56 \\
\hline Quality of packaging of food items & &
\end{tabular}

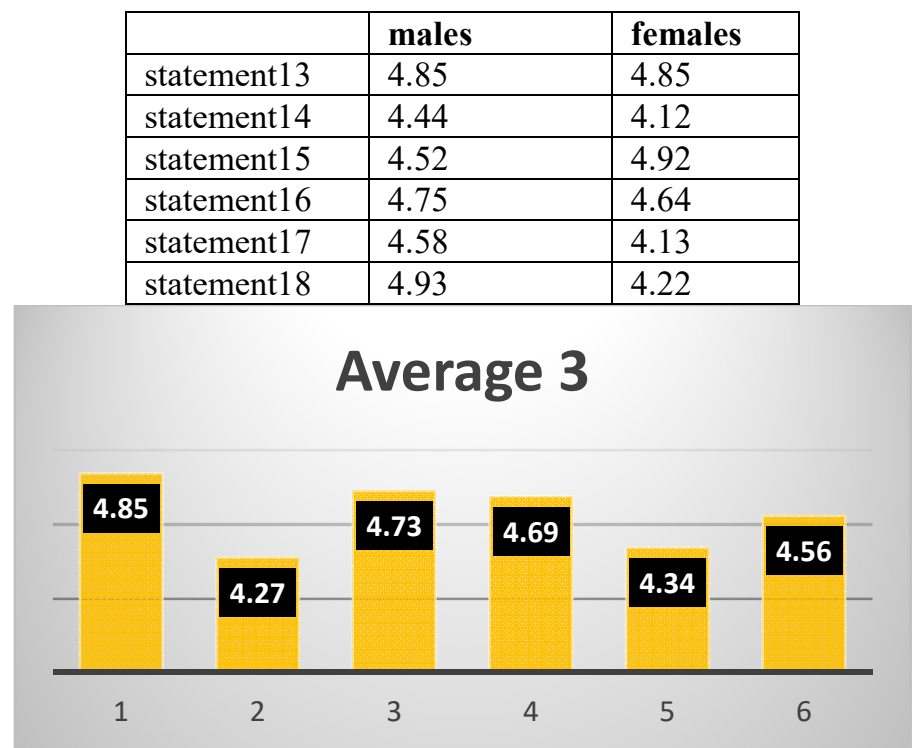

Table 5. reveals a high level of satisfaction regarding the catering. 21 passengers graded statement number 14 with the score of 1 and 24 passengers with the score of 2 . Which reveal a lack of variety in the menu. Female passengers were more dissatisfied with the variety of the menu with average score of (4.12) compared to male passengers. In the open ended part of the survey 50 passengers complained about the food not being healthy enough, which reveal the need to add healthier items in the menu. The average for statement 17 was relatively lower compared to other statements, which may indicate a slight problem in the quality of food especially with female passengers. 
Table 6. Showing the overall average for station, service on board and catering.

\begin{tabular}{|c|c|c|c|}
\hline & & average & $\begin{array}{l}\text { overall } \\
\text { average }\end{array}$ \\
\hline \multirow[t]{6}{*}{ STATION } & Staff attention on Station & 4.82 & \multirow[t]{6}{*}{4.69} \\
\hline & Process of ticket issued at stations & 4.73 & \\
\hline & Cleanliness inside the station & 4.48 & \\
\hline & Uniform and dress code of the staff & 4.62 & \\
\hline & Easy and quick access to the train & 4.73 & \\
\hline & Information on station & 4.77 & \\
\hline \multirow[t]{6}{*}{ ON BOARD } & Staff attention on board & 4.63 & \multirow[t]{6}{*}{4.68} \\
\hline & Entertainment on board & 4.22 & \\
\hline & Info on board during the trip & 4.86 & \\
\hline & Uniform and dress code of the staff & 4.67 & \\
\hline & Cleanliness on board & 4.76 & \\
\hline & Comfortability during the trip & 4.91 & \\
\hline \multirow[t]{6}{*}{ CATERING } & Presentation of the food & 4.85 & \multirow[t]{6}{*}{4.57} \\
\hline & Variety of the Menu & 4.27 & \\
\hline & Courtesy of the staff & 4.73 & \\
\hline & Uniform and dress code of the staff & 4.69 & \\
\hline & Quality of the food & 4.34 & \\
\hline & Quality of packaging of food items & 4.56 & \\
\hline
\end{tabular}

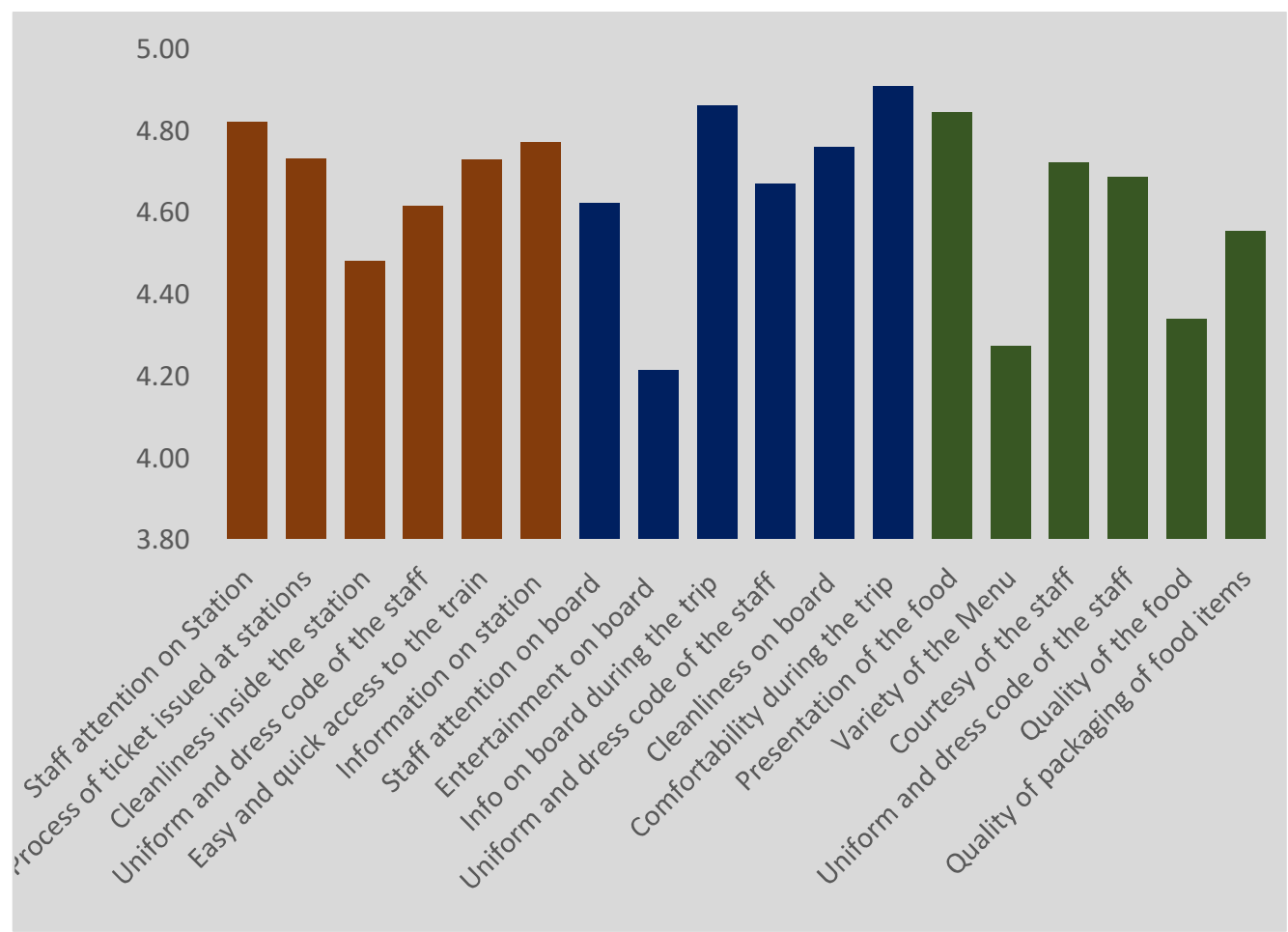

Figure. Service demonstration customer satisfaction overall results.

Table 6. By taking a look of the overall average result of each one of the three dimensions measured and compare the averages to one another, we can say that the overall average is quite high in each of the three dimensions. The station and on board services average score is higher than the catering with a score of 4.69 and 4.68 respectively compared to a score of 4.57 for the catering. Two major areas that contributed to the relatively lower score of catering dimension compared to the other two dimensions are variety of the menu and quality of food. Hence, we can say that passengers had a problem with lack of menu items and the quality of food available in the menu.

Entertainment available on board scored the lowest compared to the other 17 areas addressed in this paper with a score of 4.22 indicating passengers were unsatisfied with the entertainment available on board.

By looking to the previous bar graph, we can easily identify three major areas that are inferior and need to be improved, which are: 
- Entertainment on board

- Variety of the menu

- Quality of food.

\section{Conclusion}

The overall findings show that the haramin high-speed rail passengers perceive that the HHR is providing good quality services that meet their expectation. The data analysis indicate that level of satisfaction is relatively high in all of the three categories addressed in the survey. However, findings of this study will helpful for the managers in future planning. In the current situation, there are many areas available for further development by HHR authorities. To conclude, the HHR authorities should take necessary actions to develop and resolve the problems faced by the passengers.

\section{Recommendation}

Several areas that need more attention and improvement were identified:

1. The level of cleanliness need to be improved inside the stations especially in the restroom area. The low level of cleanness can be due to the fact that constriction work in some stations is not yet finalized.

2. An improvement is much needed in the entertainment area. That's can be done by installing screens in the economy class and providing a USB output.

3. The problem of not having network coverage for cellular phones during the trip need to addressed.

4. Lack of variety in the food and drinks menu need to be addressed by adding some healthy alternatives and increasing the quality of food in general.

\section{Limitation of the Study}

There are some limitations of this study as it was conducted with limited number of passengers. However, this research gives some insights to develop and improve the quality of services in the near future and to achieve even higher level of customer satisfaction on the long term.

\section{References}

- Chitra, B. Vani, U. (2013) “A Study On Customer Satisfaction Towards The Services Provided By Indian Railways.” International Journal of Multidisciplinary Management Studies, Vol.3, Issue, 11.

- Geetika, S.N. (2010). "Determinants of Customer Satisfaction on Service Quality: A Study of Railway Platforms in India." Journal of Public Transportation, Vol. 13, No. 1. Pg.97-113.

- Gegeckaitè, L. (2011). "Factors of customer satisfaction on services." Global Academic Society Journal: Social Science Insight, Vol. 4, No. 12, pg. 4-13.

- $\quad$ Kalaiselvi, A., Sandhya, D. and Athira, C.G. (2017) "Passengers Satisfaction Towards Railway Services With Reference To Coimbatore Junction.” International Journal of Development Research, Vol.07, Issue, 10, pg.16328-16330.

- Maheswari, B. Dinesh Kumar, G.R. (2016) “A study on Passenger Satisfaction of Amenities provided by Southern Railways with special reference to Coimbatore Junction.” International Journal of Applied Research, 2(1) pg. 288-292.

- Marinov, M. Lima, T. Kühl, B. Bogacki, A. and Onbasi, C. (2014). “Analysis of Customer Services in Railway Passenger Stations Using a Holistic Method - Application to Newcastle Central Station.” Transport Problems, Vol. 9 Special Edition. Pg. 62-70.

- Priyadharshini, J. Selladurai, M. (2016). "Service Quality and Passengers Satisfaction of Southern Railways by ServQual Model.” International Journal of Trend in Research and Development, Vol 3(6).

- Rajeswari, V. Santa kumara, K. (2014). "Satisfaction and Service Quality in Indian Railways - A Study on Passenger Perspective.” IOSR Journal of Economics and Finance, Vol. 4, Issue, 1, pg. 58-66.

- Selvarani, C. Murugan, K. (2017) "Passenger's Perception towards Indian Railway Service With Reference To Villupuram Junction.” International Journal of Multidisciplinary Research and Development, Vol.4, Issue, 8, pg. 37-41.

- Vishnuvarthan, S. Selvaraj, A. (2012) "Railway Passengers' Satisfaction: A Study in Salem Division of Southern Railway.” International Journal of Advanced Research in Management and Social Sciences, Vol.1 | No.6.

- www.saudirailways.org 